\title{
The Cellular Basis for Alveolar Bone Loss in Leprosy*
}

\author{
SANDY C. MARKS, JR † AND KRISHNAN SUBRAMANIAM \\ Department of A natomy, Faculty of Medicine, \\ University of Malaya, Kuala Lumpur, Malaysia
}

\begin{abstract}
Maxillary alveolar bone biopsies from 7 patients with lepromatous, borderline or tuberculoid leprosy and 6 patients without leprosy were examined microscopically to identify cellular sources of bone loss. Osteoclasts and osteolytic osteocytes were found in greatest numbers in 3 patients with lepromatous leprosy who also had the greatest loss of alveolar bone. These cells were scarce or absent in bone biopsies from the patients with borderline or tuberculoid leprosy and from the patients without leprosy. These data are interpreted to mean that osteoclasts and osteolytic osteocytes represent the cellular basis for alveolar bone loss in leprosy.
\end{abstract}

\section{Introduction}

The discovery of resorption of the anterior nasal spine and of maxillary alveolar bone in patients with leprosy was made by Møller-Christensen (1952, 1953) in a unique and thorough examination of skeletal remains from a medieval cemetery for lepers in Naestved, Denmark. Documentation of these changes in contemporary patients was confirmed by Michman and Sagher (1957) in a study of 44 patients with lepromatous, borderline or tuberculoid leprosy. They found that resorption of nasal spine and maxillary alveolar process were greatest in patients with long-standing disease and most common in patients with lepromatous leprosy. Loss of alveolar bone was greatest in the maxillary midline, resembling an inverted triangle on radiographs. This characteristic resorption was a constant finding in the severely affected patients, but it could not be attributed solely to leprosy because these patients also had severe periodontal disease, a process in which this type of vertical alveolar resorption is routinely found (Michman and Sagher, 1957).

We have demonstrated in patients with leprosy at Sungei Buloh, Malaysia, that alveolar bone loss was maximal in the maxillary anterior region and that

\footnotetext{
*Supported in part by Grant No. DE 03818 from the National Institute for Dental Research, Washington, D.C. and Grant No. 135/77 from the University of Malaya.

†S. C. M. was on sabbatical from the Department of Anatomy, University of Massachusetts Medical School, 55 Lake Avenue, Worcester, Massachusetts 01605, U.S.A. Reprint requests should be sent to him at this address.
}

Received for publication $27 \mathrm{July}, 1978$. 
patients with lepromatous leprosy had a significantly greater loss of maxillary alveolar bone than patients with either borderline or tuberculoid leprosy (Subramaniam and Marks, 1978). The objective of this report is to identify in a cytochemical study of alveolar bone the possible cellular basis for this accelerated alveolar bone loss in patients with leprosy. Our data indicate that osteoclasts and a subgroup of osteocytes are the causes of alveolar bone resorption in leprosy.

\section{Materials and Methods}

Patients with leprosy were under treatment at the National Leprosy Control Centre, Sungei Buloh, Malaysia. The type of leprosy was determined by smears and clinical examination (Jopling, 1971). A small piece $(3 \times 4 \mathrm{~mm})$ of bone was removed from the mesiolabial alveolar bone surface in 7 patients after extraction of a maxillary central incisor. Three patients had lepromatous leprosy for 5, 20 and 25 years, 3 patients had tuberculoid leprosy for 2, 22 and 30 years and 1 patient had borderline leprosy for 14 years. Alveolar bone specimens were fixed, demineralized, reacted for the histochemical demonstration of acid phosphatase activity using $\beta$-glycerophosphate as substrate, fixed again and embedded in epoxy resin as described previously (Marks, 1978). Sections $1-\mu \mathrm{m}$ thick were counter-stained lightly with $1 \%$ toluidine blue. Specificity of the histochemical reaction for acid phosphatase was studied using the following controls: incubation without substrate, incubation in a medium containing an enzyme inhibitor ( $0.1 \mathrm{M}$ sodium fluoride) and incubation with heat-inactivated $\left(90^{\circ} \mathrm{C}\right.$ for $\left.30 \mathrm{~min}\right)$ sections.

Alveolar bone samples were obtained from patients without leprosy after extraction of central incisors at the Oral Surgery Clinic of the University of Malaya Faculty of Dentistry. Bone was taken from identical sites from 6 patients who were closely matched in age and ethnic group with the leprosy patients. Treatment of bone samples after extraction was identical to that described above.

\section{Results}

At least 10 non-adjacent sections (separated by at least 10 micra) were examined for bone cells in each patient. Osteoclasts were found in large numbers in the 3 patients with lepromatous leprosy, 1 or 2 were present in the patient with borderline and 1 patient with tuberculoid leprosy and no osteoclasts were found in the remaining 2 patients with tuberculoid leprosy. Up to 30 non-adjacent sections were examined in the latter 2 patients to reduce the possibility of missing an osteoclast if present. The osteoclasts found were of normal morphological appearance and were often in groups (Fig. 1). Most were on the external surface of the alveolus (Fig. 1), but a few were found in resorbing canals within alveolar bone (Fig. 2). These cells were of normal cytochemical appearance with respect to intracellular distribution of the lysosomal enzyme acid phosphatase. The enzyme was concentrated next to the bone surface (Fig. 3 ) with some enzymatic activity distributed generally within 


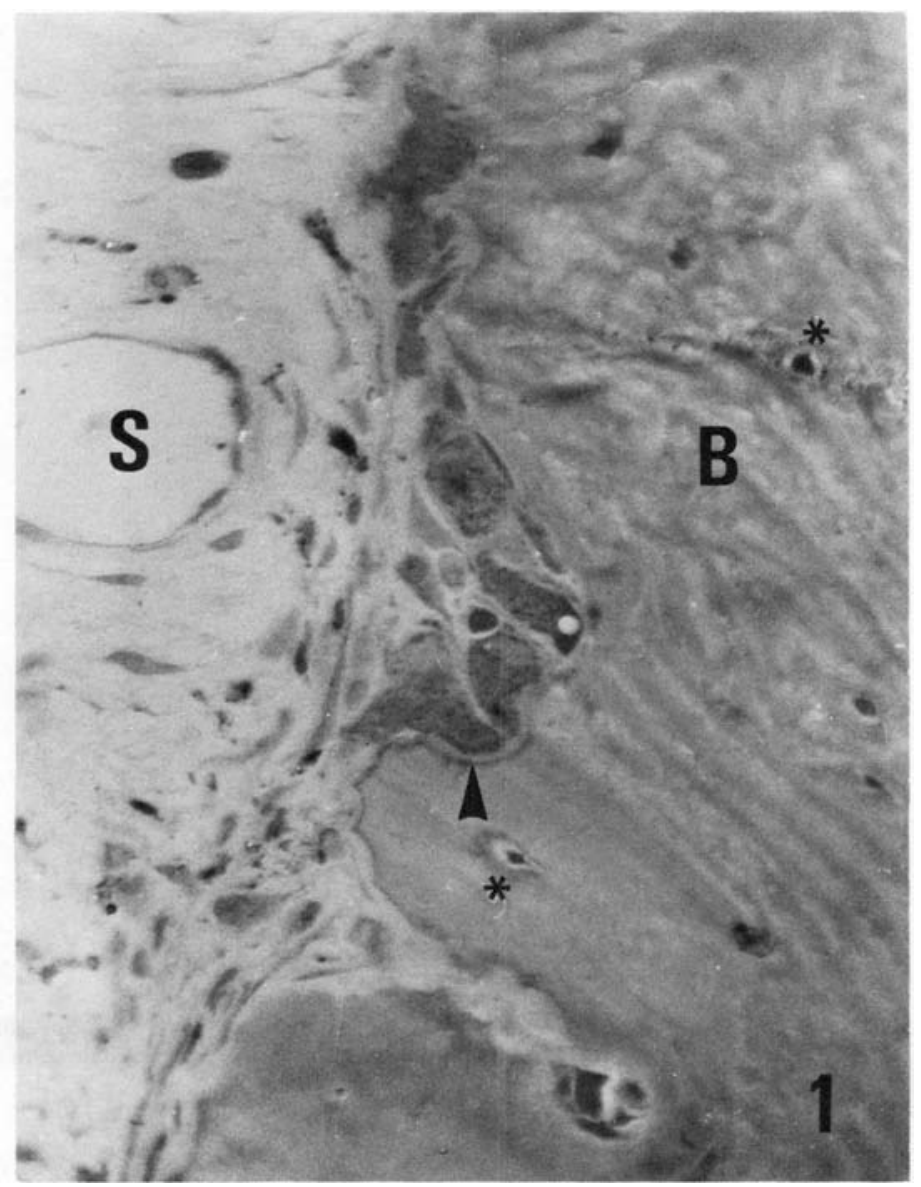

Fig. 1. Photomicrograph of the external surface of an alveolar bone biopsy. Seven osteoclasts are aligned next to the bone (B) surface above the arrow head. Black dots in the cytoplasm of these cells are lysosomes revealed by the histochemical reaction for the enzyme acid phosphatase. Enzymatic activity in the osteoclast next to the arrow is concentrated in a linear array next to the bone surface. The lacunae of adjacent osteocytes $\left(^{*}\right)$ are enlarged. A large venous sinus (S) is conspicuous in the loose connective tissue. All photomicrographs are from patients with lepromatous leprosy. $\times 300$.

the cytoplasm (Figs 1-3). Osteocytes with enlarged lacunae were frequently observed in bone near osteoclasts (Figs 1 and 2). Osteocytes without enlarged lacunae were found in all bone samples. Alveolar bone support between the maxillary central incisors of these 7 patients was measured (Subramaniam and Marks, 1978) and expressed as the percentage loss of alveolar bone. Bone loss was 28,29 and $37.5 \%$ in the 3 lepromatous patients, $19 \%$ in the borderline and 14,16 and $20 \%$ in the 3 tuberculoid patients. 


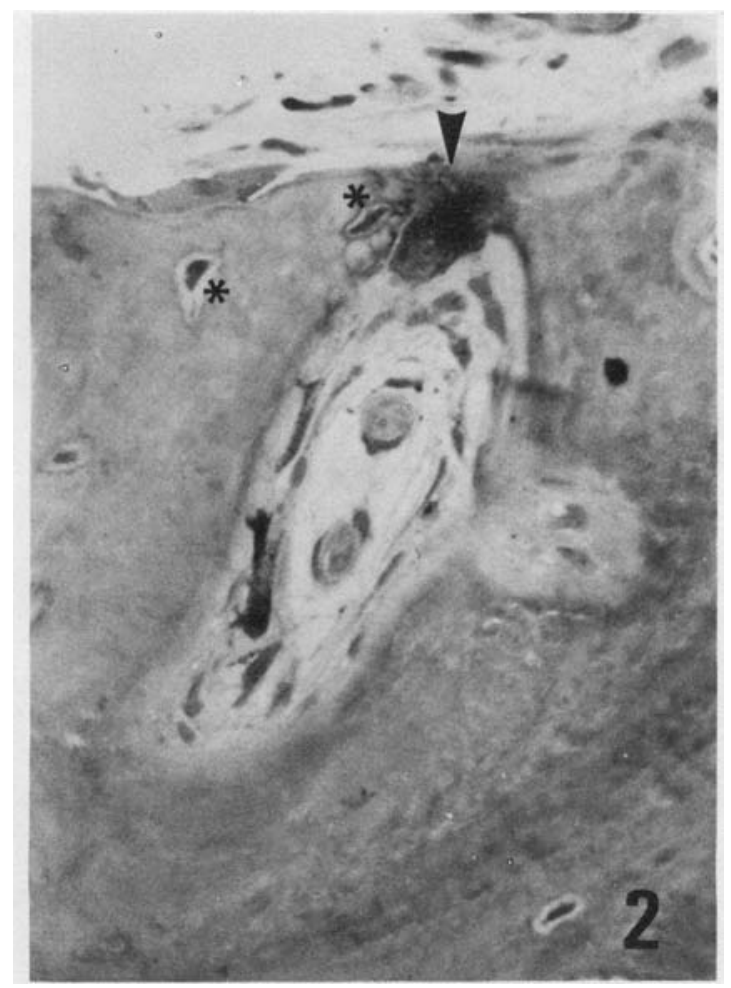

Fig. 2. An osteoclast (arrow head), very reactive for the enzyme acid phosphatase, is resorbing a thin plate of bone between a resorption canal and the surface. Lacunae of adjacent osteocytes $\left({ }^{*}\right)$ are greatly enlarged. $\times 300$.

The frequency of osteoclasts observed in these patients was compared with that in alveolar bone from identical sites in 6 patients without leprosy, matched for age and ethnic group. We found osteoclasts in only 2 of these patients (a total of 3 osteoclasts) after microscopic examination of over 15 non-adjacent sections from each patient. These osteoclasts were indistinguishable morphologically and cytochemically from those shown in Figs 1-3. In 3 of these 6 patients over $40 \%$ of the osteocyte lacunae were empty. The lack of pre-extraction X-rays precluded measurement of alveolar bone loss in these patients. However, because most of the extracted teeth were carious and the gingival condition was good with no pockets deeper than $2 \mathrm{~mm}$, we infer that these patients without leprosy did not have advanced periodontal disease. These results are summarized in Table 1. Osteoclasts were most numerous in patients with the greatest loss of alveolar bone, i.e. the patients with lepromatous leprosy. Osteoclasts were rare in alveolar bone samples from patients with borderline and tuberculoid leprosy and in patients without leprosy. 


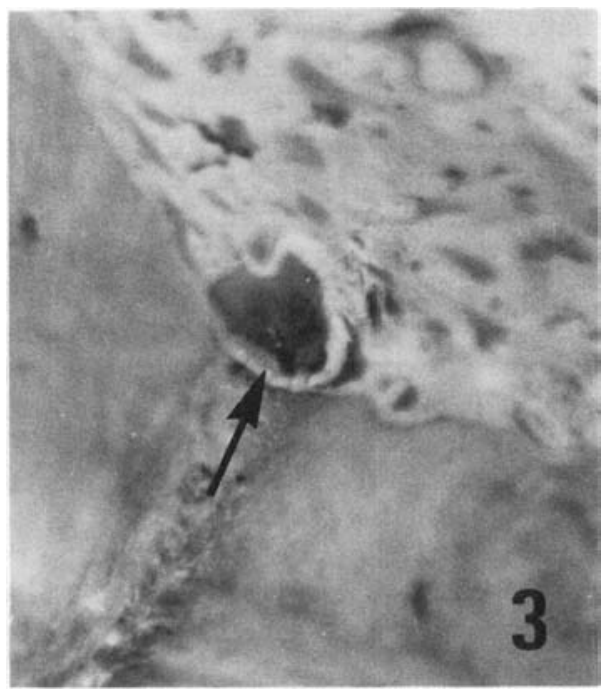

Fig. 3. A slight separation of this osteoclast from the bone surface reveals some of the thin cytoplasmic strands of the striated border that connect it to the bone surface. Note the concentration of acid phosphatase activity (above arrow head) in the cytoplasm next to bone. $\times 400$.

TABLE 1

\begin{tabular}{lcccc}
\hline & Lepromatous & Bype of leprosy & & $\begin{array}{c}\text { Patients } \\
\text { without } \\
\text { leprosy }\end{array}$ \\
\hline $\begin{array}{l}\text { Number of patients } \\
\begin{array}{l}\text { Range of number of } \\
\text { osteoclasts }\end{array}\end{array}$ & 3 & 1 & Tuberculoid & 3 \\
$\begin{array}{l}\text { Percent alveolar } \\
\text { bone loss* }\end{array}$ & $12-25$ & 1 & $0-2$ & $0-1$ \\
& $28-37.5$ & 19 & $16-20$ & Not \\
\hline
\end{tabular}

* Data taken from Subramaniam and Marks, 1978.

\section{Discussion}

Recent evidence has shown that osteoclasts and a subgroup of osteocytes are the major cell types responsible for bone resorption (Marks and Walker, 1976). Electron microscopy has demonstrated that osteoclasts possess a specialization of the plasma membrane next to the bone surface which localizes its release of lysosomal enzymes during bone resorption (Lucht, 1971). Studies of osteocytes have shown that they can be divided functionally into 3 groups; osteogenic osteocytes which behave like osteoblasts, osteolytic 
osteocytes which have enlarged lacunae and resorb bone, and resting osteocytes (Jande, 1971). Acid phosphatase, a lysosomal enzyme, is released from bone cells during bone resorption (Lucht, 1971; Vaes, 1968).

Our demonstration of osteoclasts and osteocytes with enlarged lacunae in alveolar bone from patients with bone loss strongly suggests that these cells are the basis for the advanced alveolar bone loss present in patients with lepromatous leprosy (Subramaniam and Marks, 1978). The method used to identify osteoclasts in this study, a combination of cytochemical staining of the lysosomal enzyme acid phosphatase and excellent preservation of cytological detail has many advantages over classical methods to identify these cells (Marks, 1978). Thus, it is likely that our failure to find many osteoclasts in alveolar bone from patients with borderline and tuberculoid leprosy and from patients without leprosy represents a reduction in numbers rather than a failure of the survey or identif ying methods used.

The absence of almost half the osteocyte population in three patients without leprosy is puzzling. Less than $10 \%$ of osteocyte lacunae are usually empty in the osteocyte population (Jande, 1972). This observation coupled with the absence of osteoclasts could indicate that bone turnover in these patients is extremely low.

Osteoclastic resorption in maxillary alveolar bone in patients with lepromatous leprosy may be related to nasal spine resorption and the presence of large numbers of $M$. leprae in the adjacent nasal mucosa in these patients (Job et al., 1966; Michman and Sagher, 1957; Rendall and McDougall, 1976; Southam and Venkataraman, 1973). Osteoclast function might be specifically accelerated in maxillary alveolar bone and nasal spine by release of some product from the neighbouring mycobacteria. This hypothesis might be tested by organ culture of bone with $M$. leprae.

\section{Acknowledgements}

We take pleasure in thanking the following for their contribution to this study: Drs M. F. R. Waters and V. Møller-Christensen for valuable discussions, the Director, staff and patients of the National Leprosy Control Centre, Sungei Buloh, Malaysia, for their support and enthusiastic co-operation, and $\mathrm{Mr}$ Chiew Hock Koon for superb clinical assistance; at the University of Malaya, Mrs Wong Sow Mee for excellent technical assistance, the Department of Anatomy for use of its research facilities, the Oral Surgery Department of the Faculty of Dentistry for assistance and use of its facilities, and the Department of Medical Illustration for photographic assistance.

\section{Ref erences}

Jande, S. S. (1971). Fine structural study of osteocytes and their surrounding bone matrix with respect to their age in young chicks. J. Ultrastruct. Res. 37, 279.

Jande, S. S. (1972). The effects of parathormone on osteocytes and their surrounding bone matrix. An electron microscopic study. Z. Zellforsch. mikrosk. Anat. 130, 463.

Job, C. K., Karat, A. B. A. and Karat, S. (1966). The histopathological appearance of leprous rhinitis and pathogenesis of septal perforation in leprosy.J. Lar. Otol. 80, 718.

Jopling, W. H. (1971). Handbook of Leprosy. Wm Heinemann Medical Books Ltd, London.

Lucht, U. (1971). Acid phosphatase of osteoclasts demonstrated by electron microscopic histochemistry. Histochemie 28, 103. 
Marks, S. C. Jr and Walker, D. G. (1976). Mammalian osteopetrosis: a model for studying cellular and humoral factors in bone resorption. In The Biochemistry and Physiology of Bone, 2nd edit., Vol. 4, p. 227. G. Bourne, ed. Academic Press, New York.

Marks, S. C. Jr (1978). The cellular basis for bone loss in leprosy. Int. J. Lepr. (submitted for publication).

Michman, J. and Sagher, F. (1957). Changes in the anterior nasal spine and the alveolar process of the maxillary bone in leprosy. Int.J. Lepr. 25, 217.

Møller-Christensen, V. (1953). Ten Lepers from Naestved in Denmark. A Study of Skeketons from a Medieval Danish Leper Hospital. Danish Science Press, Ltd, Copenhagen.

Møller-Christensen, V., Bakke, S. N., Melsom, R. S., and Waaler, E. (1952). Changes in the anterior nasal spine and alveolar process of maxillary bone in leprosy. Int. J. Lepr. 20, 335.

Rendall, J. R. and McDougall, A. C. (1976). Reddening of the upper central incisors associated with periapical granuloma in lepromatous leprosy. Brit. J. Oral Surg. 13, 271.

Southam, J. C. and Venkataraman, B. K. (1973). Oral manif estations of leprosy. Brit. J. Oral Surg. 10, 272.

Subramaniam, K. and Marks, S. C. Jr (1978). Alveolar bone loss in leprosy. A clinical and radiological study. Lepr. Rev. 49, 287.

Vaes, G. (1968). On the mechanism of bone resorption. The action of PTH on the excretion and synthesis of lysosomal enzymes and on the extracellular release of acid by bone cells. $J$. Cell Biol. 39, 676. 